JPKM, Vol.4, No.1, September 2018, Hal $72-87$ DOI: http://doi.org/10.22146/jpkm.33288

ISSN 2460-9447 (print), ISSN 2541-5883 (online)

Tersedia online di http://jurnal.ugm.ac.id/jpkm

\title{
Uji Silang Digital sebagai Alternatif Uji Banding Manual Pemeriksaan Mikroskopis Malaria di Kulon Progo
}

\author{
Elsa Herdiana Murhandarwati ${ }^{1 *}$, Anis Fuad ${ }^{2}$, Guntur Budi Herwanto ${ }^{3}$, Rizqiani Amalia \\ Kusumasari ${ }^{4}$, Mahardika Agus Wijayanti ${ }^{5}$, dan Supargiyono ${ }^{6}$ \\ ${ }^{1,2,3,4,5,6}$ Fakultas Kedokteran, Universitas Gadjah Mada \\ "herdiana.elsa@gmail.com
}

Submisi: 17 Februari 2018; Penerimaan: 13 Agustus 2018

\begin{abstract}
ABSTRAK
Diagnosis malaria yang akurat merupakan salah satu strategi yang memegang kunci dalam strategi eliminasi. Program nasional menetapkan bahwa diagnosis mikroskopis adalah gold standard diagnosis untuk malaria. Hilang timbulnya kasus malaria di daerah pre-eliminasi malaria menyebabkan tenaga laboratorium/mikroskopis kurang terpapar pengalaman mengidentifikasi malaria. Namun demikian, sistem uji silang (cross-check) sebagai bagian kendali mutu ini masih mempunyai kendala, antara lain jarak, waktu, serta biaya transportasi untuk pengiriman slide ke Dinas Kesehatan Propinsi sebagai laboratorium rujukan. Kurang optimalnya sistem uji silang nasional sebagai usaha penjaminan mutu menyebabkan keterampilan identifikasi yang tidak berkembang dan turunnya motivasi. Tim IbM Fakultas Kedokteran UGM telah berhasil mengembangkan suatu sistem uji silang mikroskopis malaria berbasis digital. Metode ini mampu menjembatani hambatan jarak, waktu, dan biaya transportasi pengiriman slide yang akan diuji silang. Mitra yaitu tenaga mikroskopis Puskesmas di Kulon Progo, difasilitasi dengan perangkat digital yang akan dipasang di mikroskop untuk mengambil gambar sediaan mikroskopis dan dilatih menggunakan sistem uji silang secara digital. Keberhasilan implementasi uji silang secara digital ini diharapkan mampu meningkatkan keakuratan diagnosis mitra dan membantu pemerintah dalam program eliminasi malaria terutama di Kulon Progo. Sistem ini meningkatkan kualitas penegakkan diagnosis dan berpengaruh pada pemantapan mutu eksternal (PME).
\end{abstract}

Kata Kunci: uji silang digital, Kulon Progo, eliminasi malaria, mutu, tenaga mikroskopis

\begin{abstract}
Malaria is an infectious disease in tropical countries including Indonesia which causes serious clinical manifestations and even death. As microscopic diagnosis is a gold standard diagnosis for malaria, thus accurate microscopic examination is important. Disappearance of malaria cases in malaria pre-elimination areas causes laboratory workers/microscopists are less exposed to experience in identifying malaria. As part of quality assurance, continuous quality control is expected to maintain the accuracy of malaria diagnosis in endemic areas. However, the cross-check sistem as a part of this quality control strategy still has constraints, such as: transportation costs, limited human resources and irregularity. IbM team of Faculty of Medicine UGM has successfully developed a digital microscopic cross-check sistem. This
\end{abstract}


method is able to bridge the distance and time constraint also transportation costs of slide submissions to be cross-checked to the referral laboratory. Our study partners were microscopists of Kulon Progo Primary Health Centers (Puskesmas) facilitated with digital devices installed in a microscope. Partners were trained to: 1. take microscopic images of suspected malaria parasites and 2. familiarize with digital cross-check sistem. The successful implementation of digital malaria cross-check is expected to improve the accuracy of malaria diagnosis and assist the Government in malaria elimination program especially in Kulon Progo.

Keywords: digital cross-check, Kulon Progo, malaria elimination, quality control, microscopist

\section{PENDAHULUAN}

Malaria masih merupakan masalah kesehatan yang serius di Indonesia. Penyakit yang ditularkan oleh nyamuk Anopheles betina ini mengakibatkan morbiditas dan mortalitas terutama pada anak dan ibu hamil. Penyakit ini masih endemis di sebagian besar wilayah Indonesia (Elyazar dkk., 2011). Kabupaten Kulon Progo, dengan penduduk sebanyak 459.231 jiwa, adalah daerah endemis malaria yang merupakan wilayah bagian Provinsi Daerah Istimewa Yogyakarta yang terletak paling barat dengan batas sebelah barat dan utara adalah Propinsi Jawa Tengah dan sebelah selatan adalah Samudera Indonesia. Secara geografis terletak antara $7^{0} 38^{\prime} 42^{\prime \prime}-7^{0} 59^{\prime} 3^{\prime \prime}$ lintang selatan

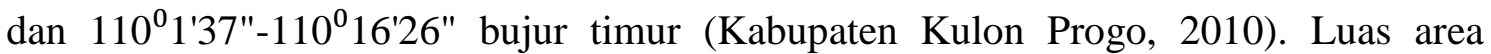
adalah 586, $28 \mathrm{~km}^{2}$ yang meliputi 12 kecamatan dan 87 desa serta topografi bervariasi dengan ketinggian antara 1-1000 meter di atas permukaan laut. Wilayah utara meliputi Kecamatan Girimulyo, Kokap, Kalibawang, dan Samigaluh, yang dikenal dengan kawasan perbukitan Menoreh. Wilayah tengah meliputi Kecamatan Nanggulan, Sentolo, Pengasih, dan sebagian Lendah, sedangkan wilayah selatan meliputi Kecamatan Temon, Wates, Panjatan, Galur, dan sebagian Lendah yang merupakan dataran rendah (Kabupaten Kulon Progo, 2010). Daerah Kulon Progo di wilayah utara yang termasuk di daerah Menoreh, yang berbatasan dengan Jawa Tengah ini juga memberi dinamika dan kompleksitas tersendiri dalam usaha pengendalian malaria (Murhandarwati dkk., 2015).

Penanganan intensif yang sudah dimulai sejak tahun 2000 melalui program nasional maupun daerah melalui kegiatan: pengadaan obat, kelambu, penyemprotan rumah (Indoor Residual Spraying) dan operasionalnya, ITN dan pemeliharaannya, 
penambahan Juru Malaria Desa (JMD), Survei Darah Massal (Mass Blood Survey) dan Pengobatan Masal (Mass Drug Administration) berhasil menekan kasus malaria selama hampir satu dekade (Murhandarwati dkk., 2015), sehingga pada tahun 2000-2008 terlihat angka penurunan kasus malaria di Kulon Progo. Namun, pada 2009-2011 terjadi peningkatan jumlah kasus malaria (Dinas Kesehatan, 2015). Pada Februari 2012, status KLB malaria ditetapkan di wilayah Kecamatan Kokap, Kabupaten Kulon Progo, Provinsi DIY (Murhandarwati dkk., 2014).

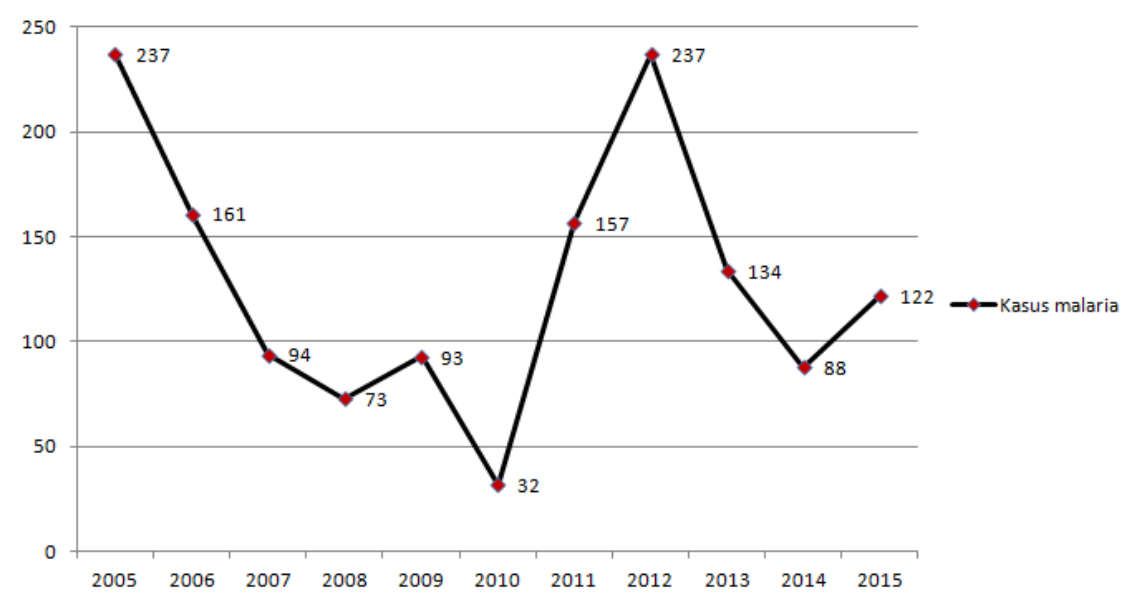

Sumber: Data sekunder diolah (2017)

Gambar 1. Kasus Malaria di Kulon Progo dalam sepuluh tahun terakhir.

Target eliminasi di DIY pada tahun 2015 diundur menjadi 2018 oleh karena terjadi kenaikan kasus pada tahun 2012 dan 2015

Pemerintah Indonesia berkomitmen untuk mengeliminasi malaria dari Indonesia pada 2030 dan eliminasi malaria di Pulau Jawa ditargetkan tercapai pada 2015. Khusus untuk di Provinsi Daerah Istimewa Yogyakarta, dari 5 kabupaten, sudah ada 3 kabupaten yang diberi sertifikat karena telah berhasil mengeliminasi malaria. Namun, di Kabupaten Kulon Progo sertifikasi bebas malaria belum diberikan mengingat daerah Kokap masih berkontribusi pada kejadian malaria bahkan sempat terjadi KLB.

Salah satu strategi pemberantasan malaria secara efektif adalah memutus siklus penularan termasuk pengobatan cepat dan tepat. Pengobatan cepat dan tepat ini hanya bisa dicapai apabila diagnosis ditegakkan secara akurat (Ariyanti dkk., 2012). Oleh karena itu, keterampilan dan kompetensi sumber daya manusia merupakan hal penting yang perlu diperhatikan (Chadijah dkk., 2006). Sumber daya manusia yang terlatih ini penting dalam menangkap kasus baru malaria dan mengidentifikasi parasit malaria 
(Mau \& Murhandarwati, 2013; Mau \& Murhandarwati, 2015a; Mau \& Murhandarwati, 2015b; Nurhayati \& Hasmiwati, 2014). Puskesmas Kokap sendiri mempunyai tenaga laboratorium dan Juru Malaria Desa yang handal karena sering terpapar dengan pelatihan-pelatihan terkait malaria. Walaupun demikian, Puskesmas sekitarnya seperti Samigaluh, Girimulyo, dan Kalibawang kurang terpapar dengan malaria padahal terdapat kecenderungan bahwa kasus malaria di Kulon Progo mulai menjangkiti Puskesmas di luar Kokap. Usaha pemantapan dan penjaminan mutu secara nasional diharapkan dapat membantu kualitas pemeriksaan malaria secara mikroskopis di daerah endemis (Tuti, 2010). Ada beberapa usaha penjaminan mutu yang biasanya dilakukan oleh Dinas Kesehatan terhadap laboratorium di bawah strukturnya antara lain pelaksanaan sistem uji silang secara blinded (Ariyanti dkk., 2012).

\section{MASALAH}

Berikut adalah gambaran malaria, penegakan diagnosis mikroskopis malaria, penjaminan mutu, dan hambatan maupun kekurangan yang bisa menjadi masalah mitra, yaitu:

Mitra I: Dinas Kesehatan Propinsi Daerah Istimewa Yogyakarta

Uji silang (cross-check) slide malaria merupakan agenda program malaria secara nasional. Akan tetapi dalam pelaksanaannya, pelaksanaan uji silang ini tidak selalu dilakukan oleh karena pengiriman slide uji silang malaria ke propinsi tergantung petugas yang melakukan uji silang (cross-checker) kabupaten dan pengiriman slide malaria ke kabupaten tergantung keaktifan Puskesmas. Pengiriman slide malaria dari Puskesmas seharusnya dilakukan secara rutin tiap bulan, demikian pula dari kabupaten ke propinsi. Kesinambungan program ini sangat tergantung komitmen Puskesmas dan Dinas Kesehatan Kabupaten, serta keterbatasan pada biaya transportasi.

Umpan balik yang diberikan oleh Dinas Kesehatan Propinsi ke kabupaten, dan dari kabupaten ke Puskesmas biasanya diberikan secara singkat dengan menyebutkan standar error. Proses administrasi dari pengiriman Puskesmas ke kabupaten, sampai diterimanya umpan balik juga membutuhkan administrasi dan waktu yang cukup lama. Mitra 2: Dinas Kesehatan (Dinas Kesehatan) Kabupaten dan Puskesmas di bawahnya

Dinas Kesehatan Kabupaten bertanggung jawab untuk membina serta melakukan uji silang malaria yang dikirimkan Puskesmas di wilayahnya. Umpan balik 
yang diberikan biasanya singkat dengan menyebutkan error rate. Proses administrasi dari pengiriman Puskesmas ke kabupaten, sampai diterimanya umpan balik juga membutuhkan administrasi dan waktu yang cukup lama. Hal ini dapat menurunkan motivasi staf laboratorium/mikroskopis.

Oleh karena proses uji silang konvensional yang dilakukan selama ini memerlukan dikirimnya slide malaria secara fisik, Puskesmas pengirim tidak mempunyai bukti asli slide sebagai bentuk dokumentasinya. Demikian pula nantinya apabila cross-checker kabupaten mengirimkan slide nya ke cross-checker propinsi, maka Dinas Kesehatan Kabupaten tidak mempunyai bukti asli slide yang telah diidentifikasinya.

Kurang efektif dan efisiennya proses uji silang pemeriksaan mikroskopis malaria berkontribusi terhadap kesenjangan kualitas mutu pemeriksaan mikroskopis malaria. Tim IbM UGM telah berhasil mengembangkan sistem uji silang digital. Dengan metode baru ini, mitra yang terlibat bisa melaksanakan uji silang secara digital. Hasil uji silang diharapkan akan bermanfaat untuk peningkatan performa kerja mitra dari tenaga lab Puskesmas.

\section{METODE}

Tim UGM bersama mitra akan mengembangkan metode baru uji silang (crosscheck) malaria secara digital dengan melakukan pendekatan secara bertahap. Pendekatan ini dilakukan untuk menjamin agar inovasi yang akan diterapkan dapat diterima oleh kedua belah pihak dan dapat dievaluasi kemanfaatannya.

\subsection{Persiapan}

Tim IbM bersama mitra akan menentukan Puskesmas yang memenuhi persyaratan infrastruktur yaitu: ketersediaan dan jenis mikroskop, komputer dan internet di samping tenaga lab yang mempunyai kemampuan dalam pembuatan slide malaria dan pengetahuan IT secara minimal, serta mempunyai komitmen tinggi dalam mengadaptasi sistem baru ini. Pada tahap ini, Dinas Kesehatan propinsi dan kabupaten menetapkan Puskesmas yang akan terlibat dan bersedia berpartisipasi dari setiap tahap pelaksanaan kegiatan dengan persyaratan sebagai berikut: mempunyai mikroskop dan 
satu komputer (software kamera mikroskop akan diinstalkan), serta komitmen SDM di Puskesmas terkait.

\subsection{Pelatihan}

a. Pelatihan kepada tenaga laboratorium Puskesmas

Pelatihan yang diberikan adalah pelatihan terkait Standar Operasiona Prosedur (SOP) pembuatan slide malaria yang standar, instalasi optilab dan softwarenya, cara penyimpanan dan memodifikasi gambar slide sebelum dikirimkan ke crosschecker, mengisi sistem secara online dan mengunggahnya, serta mengecek umpan balik yang diberikan ahlinya.

b. Pelatihan pada cross-checker Dinas Kesehatan Kabupaten dan Propinsi

Pelatihan seperti poin a, dengan penambahan pelatihan SOP sebagai ahli/cross checker bagaimana cara menerima laporan, memberi umpan balik memodifikasi gambar, mengunggah, serta mengevaluasi performa pengirim.

\subsection{Pendampingan, Monitoring, dan Evaluasi}

Untuk mengevaluasi pelaksanaan serta hambatan di lapangan maka tim IbM akan melakukan monitoring dan evaluasi langsung di Puskesmas maupun di Dinas Kesehatan. Dalam Monev ini, hal-hal yang akan dievaluasi adalah aplikasi sistem di lapangan, perangkat keras dan lunak memenuhi persyaratan, keterampilan SDM dalam mengunggah gambar slide dan mengoperasikan sistem, komitmen dalam pengiriman slide, serta kendala-kendala lain yang dihadapi.

\subsection{Pemberian Umpan Balik Peserta}

Tahap ini bertujuan meminta komitmen pengguna dalam menjaga kesinambungan sistem. Masukan dari mitra juga akan digunakan sebagai masukan untuk perbaikan sistem.

\section{HASIL DAN PEMBAHASAN}

\subsection{Persiapan Website dan Sistem Uji Silang Digital}

Sebelum sistem ini diperkenalkan, tim koordinasi mengembangkan sistem, trial dan error serta melakukan perbaikan yang terus menerus untuk memfasilitasi pengguna. Sistem yang dikembangkan oleh tim yang sama pada tahun sebelumnya mengalami 
perombakan yang besar meliputi tampilan, dan fitur-fiturnya. Alur pelaporan dan penyampaian umpan balik masih sama, akan tetapi cara evaluasi diadopsi dari kebijakan nasional yaitu dengan angka sensitivitas spesifisitas untuk menggantikan error rate.

Pada situs ini, tim juga mengembangkan hal baru yaitu slide yang diunggah bisa terdiri dari beberapa foto, notifikasi bergilir untuk expert/cross checker serta penambahan ke menu reporter: Latihan Identifikasi Malaria, http://paritranaasia.org/index.php/lat yang didapat dari partner tim. Setelah website sudah bisa dioperasikan dengan dukungan server serta pemberian domain oleh DSSDI UGM, maka Tim IbM melakukan koordinasi dengan pihak mitra.

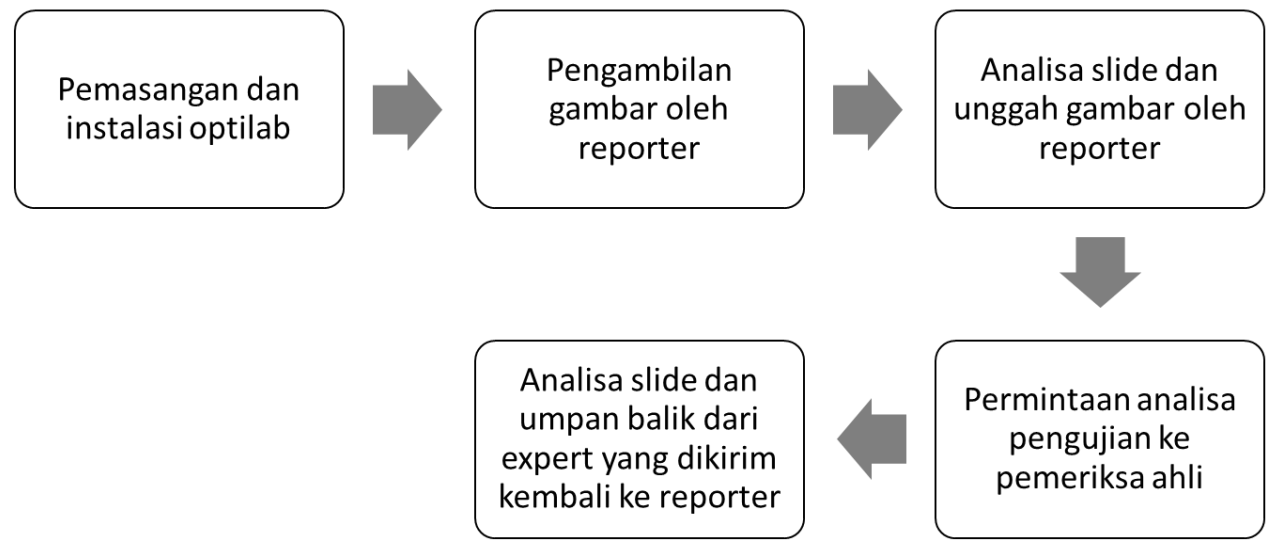

Sumber: Data sekunder diolah (2017)

Gambar 2. Alur kerja pelaksanaan sistem uji silang digital malaria

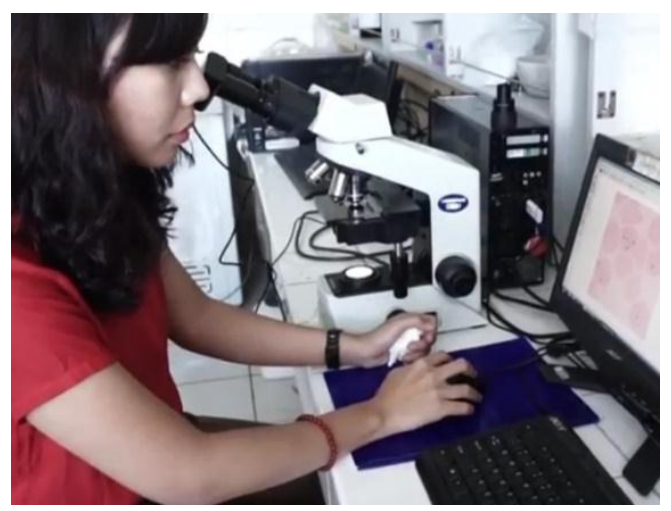

Sumber: Data primer diolah (2017)

Gambar 3. Pengoperasian pengambilan gambar dan pengunggahan gambar oleh tenaga mikroskopis dengan perangkat mikroskop, komputer, dan jaringan internet. 
Tim IbM bersama mitra terutama Kabid P2P menentukan Puskesmas yang memenuhi kriteria inklusi yaitu merupakan daerah endemis malaria, serta memenuhi persyaratan infrastruktur yaitu: ketersediaan dan jenis mikroskop, komputer dan internet di samping tenaga lab yang mempunyai skill dalam pembuatan slide malaria dan pengetahuan IT secara minimal serta mempunyai komitmen tinggi dalam mengadaptasi sistem baru ini. Ada enam Puskesmas yang ditunjuk berpartisipasi dalam kegiatan ini, yaitu: Puskesmas Kokap 1, Puskesmas Kokap 2, Puskesmas Samigaluh 1, Puskesmas Samigaluh 2, Puskesmas Girimulyo 1, dan Puskesmas Girimulyo 2. Perwakilan dari setiap Puskesmas tersebut adalah tenaga mikroskopis yang sudah terbiasa membaca preparat malaria dalam bentuk apusan tipis maupun tebal. Setiap tenaga mikroskopis tersebut mendapatkan akun masing-masing untuk mengakses ke website qamalaria.fk.ugm.ac.id.

\subsection{Pelatihan dan Diseminasi}

Diseminasi dilaksanakan pada 21 Juni 2017 di Dinas Kesehatan Kulon Progo dihadiri Kepala Dinas Kesehatan Kabupaten Kulon Progo, programer malaria dari Puskesmas, cross checker tingkat Dinas Kesehatan Kabupaten dan tenaga mikroskopis Puskesmas. Pihak-pihak yang terlibat dicantumkan pada profil website qamalaria.fk.ugm.ac.id.

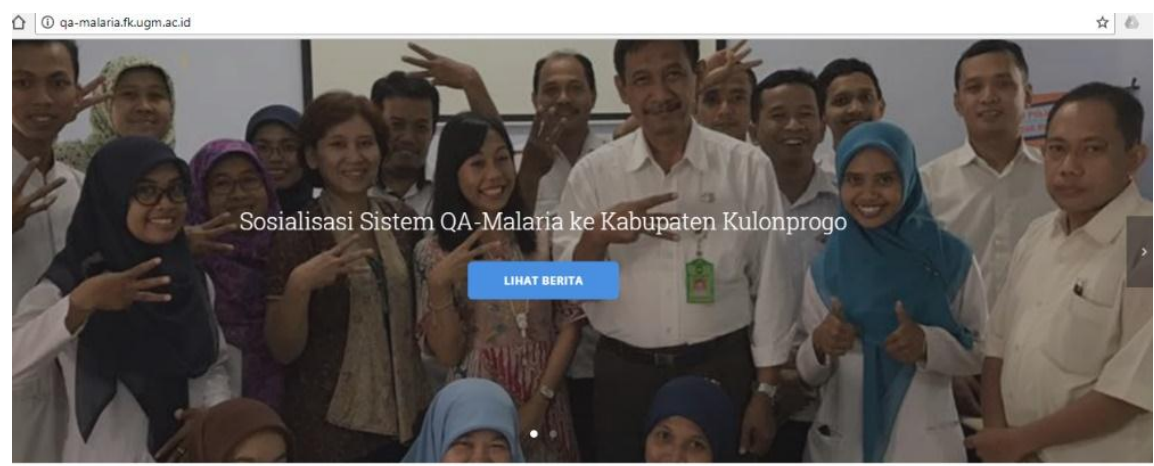

QA-Malaria

Sumber: Data primer diolah (2017)

Gambar 4. Diseminasi sistem QA malaria di Kabupaten Kulon Progo 
a. Pelatihan kepada tenaga laboratorium Puskesmas

Pelatihan yang diberikan adalah pelatihan terkait SOP pembuatan slide malaria yang standar, instalasi optilab dan software, cara penyimpanan dan memodifikasi gambar slide sebelum dikirimkan ke pemeriksa uji silang (crosschecker), mengisi sistem secara online dan mengunggahnya, serta mengecek umpan balik yang diberikan ahlinya.

b. Pelatihan pada cross-checker Dinas Kesehatan Kabupaten dan Propinsi Pelatihan seperti poin a, dengan penambahan pelatihan SOP sebagai ahli atau cross-checker bagaimana cara menerima laporan, memberi umpan balik memodifikasi gambar, mengunggah, serta mengevaluasi performa pengirim.

c. Kesepakatan dan komitmen dalam pengiriman slide secara digital dan jadwal penggunaan Optilab yaitu Samigaluh 2 dan Kokap 2 (3 Juli 2017 - 14 Juli 2017), Samigaluh 1 dan Kokap 1 (17 Juli 2017 - 28 Juli 2017), Girimulyo 1 + Girimulyo 2 (31 Juli 2017 - 11 Agustus 2017).

\subsection{Penyerahan Optilab}

Untuk memfasilitasi kegiatan cross-check digital ini, tim IbM menyerahkan dua optilab untuk dioperasikan ke enam mikroskopis yang terlibat dan satu optilab untuk operasional tim dalam penyiapan dan pengembangan aplikasi.

\subsection{Monitoring dan Evaluasi}

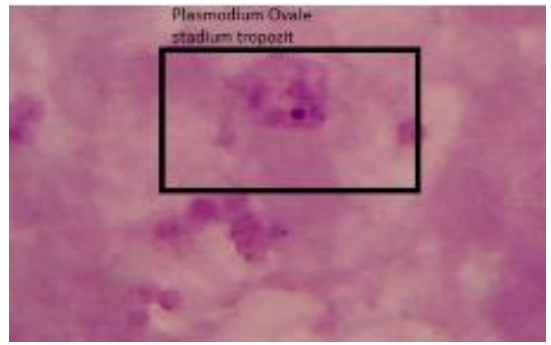

Sumber: Data primer diolah (2017) Gambar 5. A Sediaan darah tebal

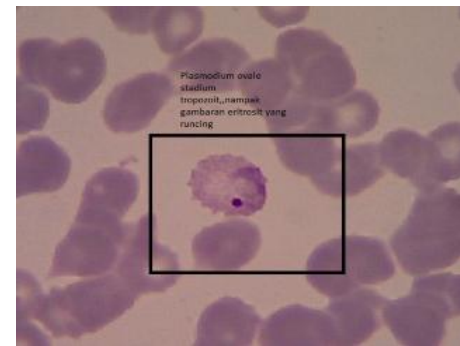

Sumber: Data primer diolah (2017) Gambar 6. Sediaan darah tipis, yang diunggah mikroskopis dan diberi keterangan dalam bentuk anotasi gambar (garis kotak dan keterangan)

Untuk memonitor pelaksanaan serta hambatan di lapangan, maka tim IbM melakukan monitoring dan evaluasi langsung di Puskesmas maupun di Dinas 
Kesehatan. Evaluasi harian meliputi aplikasi sistem di lapangan, perangkat keras dan lunak memenuhi persyaratan, keterampilan SDM dalam mengunggah gambar slide dan mengoperasikan sistem, komitmen dalam pengiriman slide, dan kendala-kendala lain yang dihadapi. Berikut adalah contoh unggah foto slide mikroskopis pada website QAmalaria dan anotasi yang dikerjakan oleh tenaga mikroskopis Puskesmas (Gambar 5), serta umpan balik dari validator Dinas Kesehatan Kabupaten yang dilatih (Gambar 6).

\begin{tabular}{|l|l|}
\hline Status Analisa & Feedback Validator 1 \\
\hline Id Pasien & 0101108 \\
\hline Kabupaten & kulon progo \\
\hline Desa & pagerharjo \\
\hline Gejala & demam \\
\hline Spesies / Plasmodium & Falciparum \\
\hline Stadium & Stadium Ring / Tropozoit Muda \\
\hline Terdapat Plasmodium & Terdapat Plasmodium \\
\hline Reporter & ahzarizkinug@gmail.com \\
\hline
\end{tabular}

Sumber: Data primer diolah (2017) Gambar 7. Contoh detail laporan (data reporter) yang harus diisi oleh mikroskopis (reporter) untuk menyertai foto slide yang diunggah

\begin{tabular}{|l|l|}
\hline Validator & muhtarashudi@gmail.com \\
\hline Validasi Plasmodium & Ada \\
\hline Pembuatan Sediaan Darah Tebal & Benar \\
\hline Pembuatan Sediaan Darah Tipis & Benar \\
\hline Feedback Spesies / Plasmodium & Falciparum \\
\hline Feedback Stadium & Stadium Ring / Tropozoit Muda \\
\hline Feedback Identifikasi Spesies & Oke \\
\hline Feedback Sediaan Darah & Oke \\
\hline Keterangan Lain & Yang tipis cari yg lebih jelas lapang pandang nya \\
\hline
\end{tabular}

Sumber: Data primer diolah (2017)

Gambar 8. Contoh detail laporan yang berisi umpan balik dari cross-checker /validator untuk dikirimkan kembali ke mikroskopis diunggah

\subsection{Hasil Pendampingan, Monitoring, dan Evaluasi}

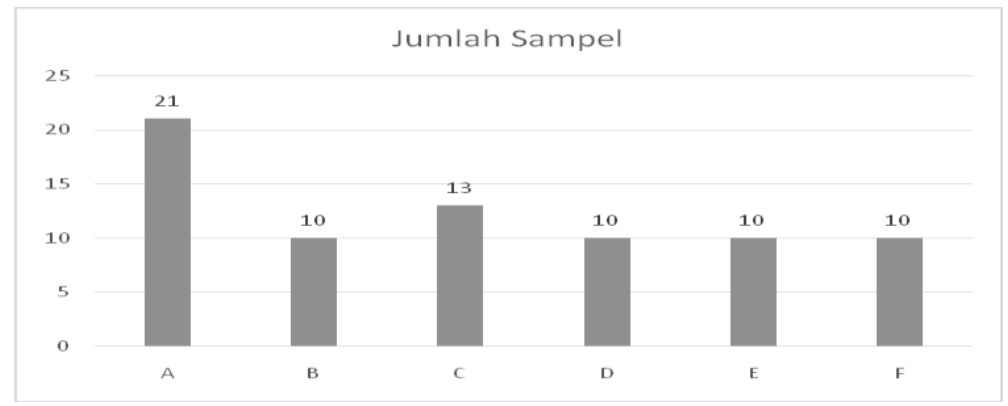

Sumber: Data primer diolah (2017)

Gambar 9. Jumlah laporan yang disampaikan oleh mikroskopis per bulan periode Juli-Oktober 2017

Dari keseluruhan analisa didapatkan umpan balik yang dapat mengevaluasi keakuratan mikroskopis dalam melakukan identifikasi Plasmodium dan spesies malaria. Performa mengenai identifikasi Plasmodium beserta spesies dinilai dengan sensitivitas (1), spesifisitas (2), serta akurasi (3). 


$$
\begin{gathered}
\text { Sensitivitas }=\frac{P B}{P B+N P} \\
\text { Spesifisias }=\frac{N B}{N B+P P} \\
\text { Akurasi }=\frac{\text { Spesies Benar }}{\text { Total Positif Spesies }} \times 100 \\
P B=\text { Positif Benar }(\text { True Positive }) \\
P P=\text { Positif Palsu }(\text { False Positve) } \\
N B=\text { Negatif Benar } \text { (True Negative) } \\
N P=\text { NegatifPalsu }(\text { False Positive) }
\end{gathered}
$$

Tabel 1. Performa Identifikasi Terdapatnya Parasit Malaria pada Sediaan Darah oleh mikroskopis per bulan periode Juli-Oktober 2017

\begin{tabular}{clrrr}
\hline Mikroskopis & Puskesmas & Sensitivitas & Spesifitas & Akurasi \\
\hline A & Puskesmas I & $100 \%$ & $100 \%$ & $100 \%$ \\
B & Puskesmas II & $100 \%$ & $100 \%$ & $95 \%$ \\
C & Puskesmas III & $100 \%$ & $100 \%$ & $100 \%$ \\
D & Puskesmas IV & $100 \%$ & $100 \%$ & $91 \%$ \\
E & Puskesmas V & $100 \%$ & $100 \%$ & $67 \%$ \\
F & Puskesmas VI & $100 \%$ & $100 \%$ & $83 \%$ \\
$\sum$ Rata-Rata & & $\mathbf{1 0 0 \%}$ & $\mathbf{1 0 0 \%}$ & $\mathbf{8 9 \%}$ \\
\hline
\end{tabular}

Sumber: Data primer diolah, Kabupaten Kulon Progo, 2017

Tabel 2. Performa Identifikasi Spesies Plasmodium Penyebab Malaria pada Sediaan Darah oleh mikroskopis per bulan periode Juli-Oktober 2017

\begin{tabular}{clrrr}
\hline Mikroskopis & Puskesmas & Sensitivitas & Spesifitas & \multicolumn{1}{c}{ Akurasi } \\
\hline A & Puskesmas I & $90 \%$ & $100 \%$ & $90 \%$ \\
B & Puskesmas II & $52 \%$ & $100 \%$ & $50 \%$ \\
C & Puskesmas III & $77 \%$ & $100 \%$ & $77 \%$ \\
D & Puskesmas IV & $80 \%$ & $100 \%$ & $73 \%$ \\
E & Puskesmas V & $40 \%$ & $100 \%$ & $27 \%$ \\
F & Puskesmas VI & $70 \%$ & $100 \%$ & $58 \%$ \\
$\sum$ Rata-Rata & & $\mathbf{6 8 \%}$ & $\mathbf{1 0 0 \%}$ & $\mathbf{6 2 \%}$ \\
\hline
\end{tabular}

Sumber: Data primer diolah, Kabupaten Kulon Progo, 2017

Dari keenam mikroskopis dan enam Puskesmas dapat dilihat performa kinerjanya dalam mengidentifikasi ada/tidaknya Plasmodium dan spesiesnya. Tabel 1 menunjukkan kemampuan mikroskopis dalam mengidentifikasi terdapatnya (ada/tidaknya) spesies malaria pada sediaan darah. Tabel 1 memperlihatkan bahwa ratarata performa akurasi mikroskopis yang terlibat adalah 89\%. Tabel 2 menunjukkan performa/kemampuan mikroskopis dalam mengidentifikasi spesies Plasmodium 
penyebab malaria, rata-rata performa akurasi berada di angka 62\%. Dari kedua hasil performa tersebut dapat dilihat bahwasanya mikroskopis telah dapat mengidentifikasi adanya parasit Plasmodium dengan sangat baik, namun dalam identifikasi spesies Plasmodium masih terdapat beberapa kesalahan.

\subsection{Pemberian Umpan Balik dari Peserta Program}

Untuk penyempurnaan program ini, peneliti mendapatkan umpan balik dari mitra/peserta program terkait kemanfaatan sistem, kekurangan yang perlu disempurnakan, kemungkinan adopsi sistem oleh pengguna lain, dan implementasinya di masa depan. Tabel 3 di bawah ini merangkum kelebihan, kekurangan, serta penyempurnaan yang perlu dilakukan oleh tim pengembang.

Tabel 3. Pendapat dan masukan peserta program sistem uji silang digital malaria terkait kelebihan dan kekurangan sistem cross-check digital pemeriksaan malaria

\begin{tabular}{ll}
\hline Masukan Peserta Program Sistem Uji Silang Digital Malaria \\
\hline Kelebihan sistem uji & Hemat waktu, langsung terdokumentasi, tidak harus melakukan \\
silang digital & pengiriman sediaan, tidak perlu mikroskop di tingkat kabupaten, hemat \\
pemeriksaan malaria & biaya uji silang, akses cepat tanpa harus ke laboratorium, dapat belajar \\
& bersama untuk penegakkan diagnosis, data dapat disimpan, langsung \\
& mendapatkan umpan balik oleh verifikator, mempercepat umpan balik \\
& laporan, potensial digunakan untuk pelaporan program yang lain, dapat \\
& langsung difoto, diupload dan di umpan balik oleh validator, menambah \\
& pengalaman, dapat langsung dilaporkan dan memperoleh umpan balik.
\end{tabular}

Kekurangan sistem uji Ketergantungan pada jaringan internet dan listrik, hanya bisa digunakan silang digital pada mikroskop tertentu, harus mempunyai peralatan fotonya sendiri, pemeriksaan malaria pada hasil yang negatif sulit disimpulkan kebenarannya karena lapang pandang terbatas (satu sediaan membutuhkan ratusan lapang pandang, cross-check hasil negatif belum terfasilitasi, kecepatan feedback antar validator tidak sama, baru dapat dikerjakan jika ada waktu luang karena banyak pelayanan di Puskesmas, menambah pekerjaan, waktu, dan beban kerja karena perlu waktu khusus, tergantung jaringan internet.

Masukan peserta Sinkronisasi dengan program nasional malaria, pengadaan alat di untuk pengembangan Puskesmas, performa kinerja dibuat terpisah setiap periode (untuk ke depan evaluasi bagi mikroskopis), untuk uji PME, pengadaan sarana prasarana, perlu dilakukan secara kontinyu, sediaan darah disediakan, pengadaan alat di tiap Puskesmas, dapat dikembangkan untuk TBC, sistem bisa dikembangan untuk memungkinkan pengiriman gambar lebih dari satu, pengkoordinasian sistem digital dengan program pemerintah (dilegalkan), sehingga semakin lancar dan wajib diikuti.

Sumber: Data primer diolah, Kabupaten Kulon Progo, 2017 
Secara umum, semua peserta uji coba (100\%) ini merasakan manfaat dan $70 \%$ di antaranya menyatakan bahwa sistem uji silang digital menghemat waktu, biaya dan tenaga dalam melakukan perjalanan/transportasi, maupun melakukan cross-check hasil pemeriksaan, feedback jadi lebih cepat, dan pelaporan kasus malaria menjadi lebih muda. Dokumentasi hasil pemeriksaan menjadi lebih mudah disampaikan oleh $30 \%$ peserta yang hadir. Selain itu, sistem ini memberikan pengalaman sekaligus pembelajaran bagi petugas dan dapat diaplikasikan pada program yang lain misalnya tuberkulosis dan helminthiasis. Peserta program mengharapkan pihak pengembang sistem (UGM) untuk melakukan advokasi ke pihak terkait/program malaria di tingkat pusat supaya sistem ini dapat diadopsi dan dijadikan tupoksi mikroskopis di Puskesmas serta validator di tingkat Dinas Kesehatan Kabupaten. Peserta yang hadir setuju jika sistem ini diadopsi menjadi program pemerintah karena menghemat waktu, biaya, tenaga dalam melakukan uji silang, umpan balik, dan kemudahan dalam pelaporan.

Ketika diadopsi menjadi program pemerintah, maka seluruh petugas wajib melaksanakan sistem. Selain itu, sistem ini meningkatkan kualitas penegakkan diagnosis dan berpengaruh pada pemantapan mutu eksternal (PME). Sistem ini juga telah mendapatkan HKI dengan Surat Pencatatan Ciptaan nomor 091306 dari Kementerian Hukum dan Hak Asasi Manusia Republik Indonesia serta mendapatkan jangka waktu perlindungan hingga 50 tahun mendatang.

\section{SIMPULAN}

Sistem uji silang secara digital secara online disebut juga QA-Malaria merupakan sistem berbasis web yang digunakan sebagai uji silang sampel malaria. Sistem ini memungkinkan seorang mikroskopis pada Puskesmas untuk mengirimkan sampel sediaan dari foto mikroskop, sekaligus melakukan anotasi letak Plasmodium malaria yang terdapat dalam sampel tersebut. Hasil validasi oleh cross-checker yang berkompeten terhadap identifikasi parasit dan spesies oleh mikroskopis akan bermanfaat untuk mengetahui performa kinerja mikroskopis.

Program ini diharapkan bermanfaat bagi:

a. Dinas Kesehatan Propinsi dan Kabupaten: informasi terkait performa bisa digunakan Dinas Kesehatan untuk menentukan kebijakan terkait rotasi SDM, 
penghematan biaya (pengiriman, transportasi, administrasi, dan birokrasi), potensi mengadopsi sistem sebagai alternatif sistem konvensional yang sudah ada.

b. Tenaga laboratorium Puskesmas: peningkatan keterampilan (skill) dan kompetensi pembelajaran yang berkelanjutan bagi petugas dan teknisi laboratorium malaria. Puskesmas tetap mempunyai slide asli yang diidentifikasi sebagai dokumentasi dan bahan pembelajaran/training mikroskopis setempat. Hal ini dimungkinkan karena uji silang digital tidak perlu mengirimkan slide malaria secara fisik akan tetapi cukup dengan mengunggah gambar mikroskopisnya saja. Implementasi uji silang digital untuk malaria diharapkan akan meningkatkan performa kerja tenaga lab di Puskesmas sehingga meningkatkan akurasi diagnosis malaria. Implementasi sistem ini akan menguntungkan Dinas Kesehatan Kabupaten dan Dinas Kesehatan Propinsi untuk mendukung Kulon Progo bebas malaria secara mandiri. Sistim ini menghemat waktu administrasi, birokrasi, dan biaya transportasi.

\section{UCAPAN TERIMA KASIH}

Kami mengucapkan terima kasih kepada Direktorat Riset dan Pengabdian kepada Masyarakat Kemenristekdikti Republik Indonesia yang telah memberikan dana hibah IbM sehingga kegiatan ini dapat berjalan, serta ucapan terimakasih, dukungan, partisipasi dan kerja sama yang terjalin baik selama Tim IbM melakukan kegiatan.

\section{DAFTAR PUSTAKA}

Ariyanti, E., Prasetyorini, B., Harun, S., Handayani, S., Tjitra, E., \& Biomedis dan Teknologi Dasar Kesehatan, P. (2012). Cek Silang Mikroskopis Sediaan Darah Malaria pada Monitoring Pengobatan Dihidroartemisinin-Piperakuin Di Kalimantan dan Sulawesi Cross-Checking Malaria Smears In Monitoring Dyhydroartemisinin-Piperakuin In Kalimantan And Sulawesi. Media Litbang Kesehatan, 22(4).

Chadijah S., Labatjo Y, Garjito T.A., Wijaya Y, Udin Y Chadijah S., Labatjo Y, Garjito T.A., Wijaya Y,U.Y. (2006). Efektifitas Diagnosis Mikroskopis Malaria di Puskesmas Donggala, Puskesmas Lembasada, dan Puskesmas Kulawi, Prov Sulteng. Jurnal Ekologi Kesehatan, 5(1), 385-393. 
Dinas Kesehatan Kabupaten Kulon Progo. (2010). Profil Kesehatan Kabupaten Kulon Progo 2011 Data tahun 2010.

Dinas Kesehatan. (2015). Profil Kesehatan Kabupaten Kulon Progo 2015.

Departemen Kesehatan Republik Indonesia. (2009). Informasi Umum Malaria, Jakarta. Direktorat Pengendalian Penyakit Bersumber Binatang, Kementerian Kesehatan, 2014. Pedoman Manajemen Malaria.

Elyazar, I.R.F., Gething, P.W., Patil, A.P., Rogayah, H., Kusriastuti, R., Wismarini, D.M., Hay, S.I. (2011). Plasmodium falciparum Malaria Endemicity in Indonesia in 2010. PloS One, 6(6). http://doi.org/10.1371/journal.pone.0021315

Mau, F., \& Murhandarwati, E.H. (2015a). Faktor-Faktor yang Mempengaruhi Ketepatan Diagnosis Malaria di Puskesmas Kabupaten Belu Nusa Tenggara Timur Factors That Influence The Accuracy Of Diagnosis Of Malaria In Community Health Center, Belu District, East Nusa Tengara Timur. Media Litbang Kesehatan, 25(2).

Mau, F., \& Murhandarwati, E.H. (2015b). Koefesien kappa sebagai indeks kesepakatan hasil diognosis Koefesien Kappa sebagai Indeks Kesepakatan Hasil Diagnosis Mikroskopis Malaria di Kabupaten Belu Nusa Tenggara Timur. Buletin Penelitian Kesehatan, 43(2).

Mau, F., \& Murhandarwati, E.H.S. (2013). Evaluation of the Performance of Malaria Microscopist in Primary Health Center and Cross Checker in Belu East Nusa Tenggara. Tropical Medicine Journal, 3(1), 16-28.

Murhandarwati, E.E.H., Fuad, A., Nugraheni, M.D.F., Sulistyawati, Wijayanti, M.A., Widartono, B. S., \& Chuang, T.-W. (2014). Early Malaria Resurgence in PreElimination Areas in Kokap Subdistrict, Kulon Progo, Indonesia. Malaria Journal, 13, 130. http://doi.org/10.1186/1475-2875-13-130

Murhandarwati, E.E.H., Fuad, A., Sulistyawati, Wijayanti, M.A., Bia, M. B., Widartono, B. S., Hawley. (2015). Change of Strategy Is Required for Malaria Elimination: A Case Study in Purworejo District, Central Java Province, Indonesia. Malaria Journal, 14, 318. http://doi.org/10.1186/s12936-015-0828-7

Nurhayati \& Hasmiwati, S.R.R. (2014). Uji Reliabilitas Diagnosis Mikroskopis Malaria Tenaga Laboratorium Puskesmas di Daerah Endemik Kota Sawahlunto Sumatera Barat. MKA, 37(1), 19-25.

Tuti, S. (2010). Beberapa Prinsip Dasar Pemantapan Kualitas (Quality AssuranceI/QA) Petugas Mikroskopis Malaria. Journal of the Indonesian Medical Association, 60(7), 329-336. 